\title{
Experimental investigation of aerosol deposition on slot- and joint-type leaks
}

\author{
François Rémi Carrié ${ }^{\mathrm{a}: \mathrm{*}}$ and Mark P. Modera ${ }^{\mathrm{b}}$ \\ a Ecole Nationale des Travaux Publics de l'Etat, Laboratoire des Sciences de l'Habitat, \\ DGCB, URA CNRS 1652, rue Maurice Audin, F-69518 Vaulx-en-Velin Cedex, France \\ ${ }^{\mathrm{b}}$ E.O. Lawrence Berkeley National Laboratory, Indoor Environment Department, \\ University of California, One Cyclotron Road, MS 90-3074, Berkeley, CA, 94720, USA
}

\section{Abstract}

This paper deals with the quantification of the sealing effectiveness of slot- and joint-type leaks by aerosol deposits. A sticky aerosol (MMD $\approx 4.9 \mu \mathrm{m} ; \mathrm{GSD} \approx 2.7$ ) was injected into a duct and blown out through machined slot- and joint-type leaks located on the duct wall. For both leak-types, the crack exit was a rectangular opening of 1.7 x $50 \mathrm{~mm}$. The pressure across the leaks was kept constant during the plugging process, while the airflow rate through the openings was continuously monitored. The deposition patterns were recorded and the average deposition efficiencies were obtained through the measurement of the particle mass collected in the crack. Instantaneous sealing rates were obtained from the leakage airflow time series. The Normalized Sealing Rate (NSR) introduced in this paper allows one to compare the instantaneous sealing efficiencies as the leaks are subjected to various boundary conditions. For our specific leak geometries and boundary conditions, the three key results of these experiments are that: a) inertial impaction near the entry point is the major cause of the decline of the leakage flow rate for either type of leak; b) the pressure variations in the 100-400 Pa range do not have a significant effect the average deposition efficiency; c) the average deposition efficiency of the slot- and joint-type leaks used are in the range of $25 \%$ and $85 \%$, respectively. We also observed that there exists a critical joint-leak size below which the NSR decreases significantly.

\footnotetext{
* Corresponding author. Tel.: + 33 472047031; fax: +33 472047041

E-mail address: Remi.Carrie@entpe.fr
} 


\section{Introduction}

Several studies have identified that leaks in HVAC air distribution systems are detrimental to their performance, and that they can result in major energy losses in residential or commercial buildings (e.g., Cummings et al., 1990; Modera, 1993; Parker et al., 1993; Carrié et al., 1999; Carrié et al., 2000; Fisk et al., 2000). For this, researchers have successfully investigated the use of aerosol particles to remotely seal leaks in HVAC duct systems from the inside (Carrié, 1994; Modera and Carrié, 1996). The current duct-sealing protocol requires blocking of all the air terminal devices and isolation of sensitive equipment (e.g., heat exchangers). The aerosol is generated from a water-based vinyl-acetate polymer liquid adhesive and blown into the system through a conveniently-located opening in the duct system, using a single device that incorporates a fan and an atomizer. The device is designed to monitor the sealing process, and measures the airtightness of the system before, during, and after aerosol injection. The aerosol is highly concentrated (typically 0.1 to $1 \mathrm{~g} \mathrm{~m}^{-3}$ ) and is made of sticky particles whose diameter typically lies between 2 and $30 \mu \mathrm{m}$. There are two major advantages to this aerosol-sealing technique. First, it is an automated remote sealing process since the particles "automatically" find the leaks in the system. Second, in residences, the technique has proved to be geometry-independent as the particles can travel within the whole system and thus access any leak site.

This technique proved to be very efficient in residential duct systems (Modera et al., 1996). However, laboratory and field experiments of aerosol duct-sealing have shown wide variations in the sealing rates. In addition, there remain unanswered questions with regard to the understanding of the deposition mechanisms in typical air distribution system leaks, and the quantification of the plugging process, whether experimentally or theoretically remains a challenge. This is partly due to the complexity of phenomena such as flow dynamics near and in the leaks or particle collection enhancement because of previous localized buildup, and to the limitations given by aerosol and flow measurement techniques.

Several researchers have investigated the sealing of cracks by aerosol deposits. For circular cracks, Vaughan (1978) has proposed a simple model that states that the total mass of aerosol passing through the leak is proportional to the cube of the duct diameter. For rectangular cracks, that mass is proportional to the crack length and the square of the crack width. Despite the simplicity of this model compared to the complexity of the phenomenon, Morewitz (1982) found that experimental data from a number of experiments with a variety of aerosol materials over a wide range of duct diameters (20 $\mu \mathrm{m}$ to $26.5 \mathrm{~cm}$ ) and a wide pressure range (about 0.3 to $700 \mathrm{kPa}$ ) correlated well with the model predictions. He found proportionality constants fitting the "cube law" in the range of $K=30 \pm 20 \mathrm{~g} \mathrm{~cm}^{-3}$; however, he noted that modifying the duct inlet shape (rounded versus sharp) strongly influenced this value. In rounded inlet case, the flow dynamics near the inlet are changed, yielding a different plug location and an aerosol mass required for plugging about five times greater than for the sharp inlet case. 
Novick (1994) pointed out that the "cube law" assumption stating that the plug grows from an initial deposit implicitly involved inertial impaction. His analysis of available experimental data supported that plugging only occurred when Davies' criteria were violated. If so, the passageway plugged according to the cube law.

Several other authors have studied the penetration of aerosols through fine capillaries and leaks (Mitchell et al., 1990; Mitchell et al., 1991; Morton and Mitchell, 1995; Clement, 1995). These studies focused on the quantification of the leakage of aerosols through radioactivity transport flasks. The diameter of the capillaries investigated by those authors are in the range of 2 to $100 \mu \mathrm{m}$ while the pressure differentials are in the range of 20 to $100 \mathrm{kPa}$.

Williams (1994) has developed a plugging theory for small tubes. However, he notes that the neglect of inertial impaction at the entry point in his theory may well be crucial. Indeed, there is experimental evidence that deposition occurs mostly at the entry point in our application.

Impaction was identified by Carrié and Modera (1998) as being a dominant mechanism for coarse-mode particle deposition in a rectangular slot $(3 \times 40 \mathrm{~mm})$. The purpose of this paper is to further investigate this phenomenon in slot- and joint-type leaks commonly found in HVAC air distribution systems. It is based on experiments performed with machined slot- and joint-type leaks located on the duct wall, both with a rectangular crack exit of $1.7 \times 50 \mathrm{~mm}$. 


\section{Laboratory setup}

The principal objective of our experimentation is to quantify the sealing effectiveness of our aerosol-sealant in slot- and joint-type leaks. The laboratory setup consists of a blower with heating elements and automatic control of the airflow rate hooked to a duct section where the aerosol is generated (Figure 1). The duct section consists of two parts: a 2meter long 25-cm-diameter thin-wall plastic tube; and a 2.5-meter long metal duct with a 30 x $30 \mathrm{~cm}$ square cross section. There are two aluminum airtight boxes with a clear acrylic lid downstream of that duct section (about $4 \mathrm{~m}$ and $4.3 \mathrm{~m}$ from the injection point), either with one slot- or one joint-type leak (Figure 2). The flow through the leaks is continuously monitored with venturi flow meters during the sealing process while the pressure across the cracks is kept constant with a PI-controlled proportional solenoid valve. In the experiments reported here, the duct airflow rate was maintained to $42 \mathrm{~L} \mathrm{~s}^{-1}$ while the pressure differentials across the leaks were maintained at 100, 200, 300, or 400 $\mathrm{Pa}$.

Several atomizing techniques have been examined; however, we found that only a few commercially-available aerosol generators were able to atomize our vinyl polymer, and none of them are able to produce a monodisperse aerosol. In this study, we used a vortex nozzle that uses counter-rotating swirls of air generated by fixed "wheels" to atomize a liquid stream. It has been the standard equipment on aerosol duct-sealing systems to date.

We used a Mark V (University of Washington) cascade impactor with 9 stages to assess the particle size distribution 4.6 meters downstream of the injection location (Pilat, 1970). Some of the stages were modified so that the resulting cut-off diameters enable us to better characterize the size distribution. The stages were weighed using a $0.1 \mathrm{mg}$ resolution scale (Mettler AE Model 240, Hightstown, NJ). Typically, the mass collected on each stage was in the range of 1 to $8 \mathrm{mg}$, while the total mass collected was about 32 mg.

The aerosol deposited in the leak was collected and weighed after each experiment. Along with the aerosol concentration measurement and the integrated airflow rate through the orifice, this enabled us to calculate the deposition efficiency as defined below. 


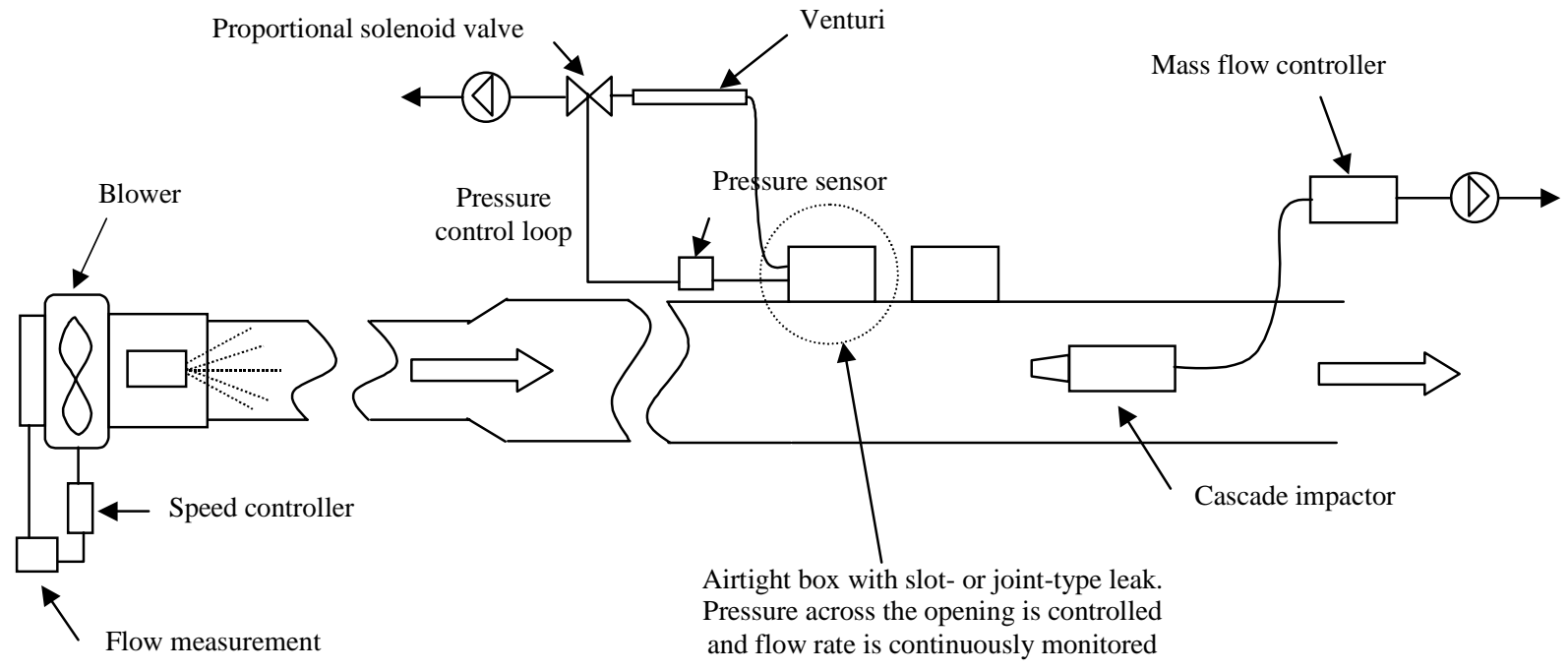

Figure 1. Schematic diagram of the experimental apparatus used to quantify the aerosol sealing rate and deposition efficiency in slot- and joint-type leaks.

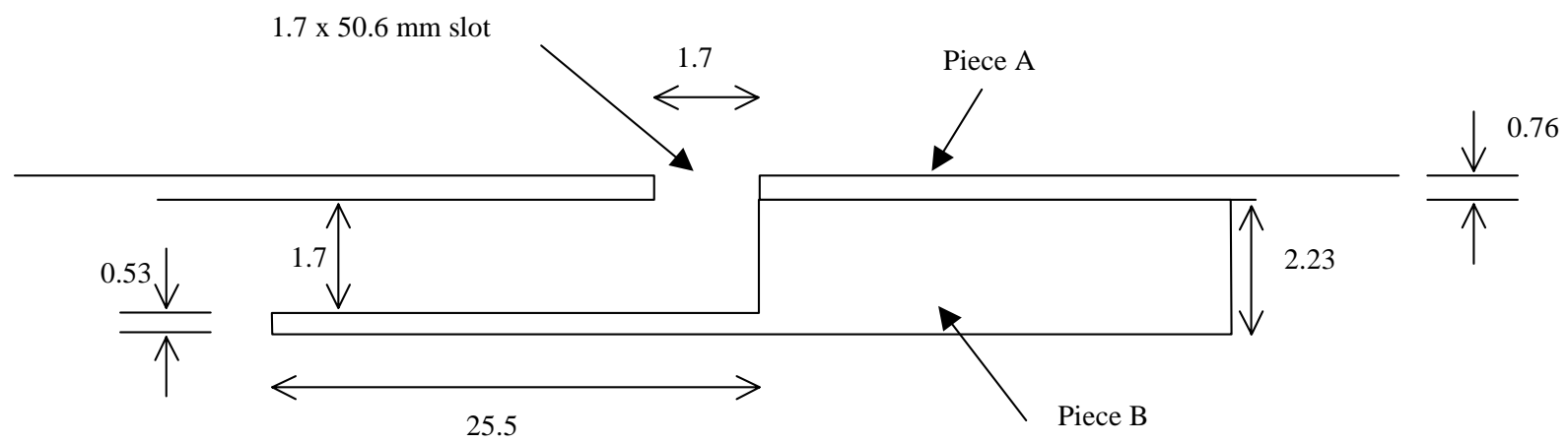

Figure 2. Characteristics of the slot- and joint-type leaks. A pocket $(25.5 \times 50.6 \mathrm{x}$ $1.7 \mathrm{~mm}$ ) was machined in a piece of aluminum $(25.5 \times 75 \times 2.23 \mathrm{~mm})$. The slotleak is obtained by removing piece $B$. Each leak exits into an airtight box connected to a flow meter (Figure 1). The box (and piece B for joint-leak tests) were dismantled after each experiment to collect the aerosol deposit. All dimensions are in $\mathrm{mm}$. 


\section{Quantification of the sealing effectiveness}

A pre-requisite to the analyses of these experiments is to define metrics to quantify the sealing effectiveness that can be used for relevant comparisons. These metrics are defined here below:

\subsection{Average deposition efficiency}

The deposition efficiency may be defined as the mass flux of material deposited in the leak versus that that would ideally pass through or deposit in the leak-i.e., the product of the aerosol mass concentration in the main stream times the airflow rate through the leak. Here, the average deposition efficiency was estimated with a) the measurement of the mass of particles collected in the crack; and b) the aerosol mass concentration and the leakage flow data to derive the mass of aerosol in the stream that would ideally exit through the crack. Besides the accuracy of the instruments, there are several potential biases to those measurements, namely:

a) The aerosol concentration near the leak may be different from that of the main stream; and

b) Some particles may deposit in the crack although they are not originally in the air stream that exits through the leak (Figure 3). This particle mass is not accounted for in the denominator of the deposition efficiency.

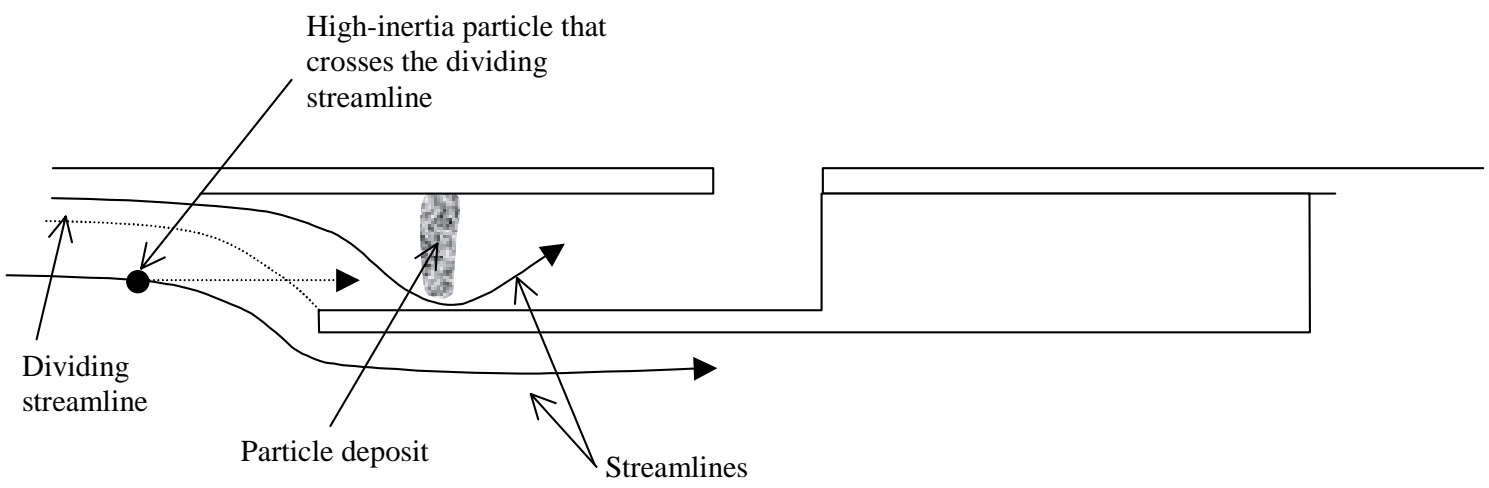

Figure 3. Example of trajectory of a high-inertia particle that deposit in the joint although not originally in the air stream that exits through the leak.

\subsection{Effective Leakage Area (ELA)}

The Effective Leakage Area (ELA) of a crack is defined as the size of a perfect nozzle that, at some reference pressure, would produce the same flow as that passing through the crack at this reference pressure. The equation linking $E L A$ with the volumetric flow rate through the crack to the pressure difference is:

$$
Q=E L A_{r e f} \sqrt{\frac{2 \Delta P_{r e f}}{\rho}}\left(\frac{\Delta P}{\Delta P_{r e f}}\right)^{n}
$$

where $Q$ is the volumetric flow rate $\left(\mathrm{m}^{3} \mathrm{~s}^{-1}\right), E L A_{\text {ref }}$ is the effective leakage area $\left(\mathrm{m}^{2}\right), \Delta P$ is the pressure difference across the leak $(\mathrm{Pa}), \Delta P_{r e f}$ is a reference pressure difference 
(Pa) (usually $25 \mathrm{~Pa}$ for ducts), $n$ is the flow exponent (-), and $\rho$ is the air density $\left(\mathrm{kg} \mathrm{m}^{-3}\right)$. This metric is commonly used to characterize cracks (Sherman, 1992; ASHRAE, $2001 \mathrm{p}$. 26.13).

\subsection{Normalized leakage flow rate}

The leakage flow rate during the sealing process normalized by the initial leakage flow rate is a measure of the size of the leak relative to its initial size. Note that if the reference pressure difference is taken as that applied across the leak, we can write:

$$
N L F R=\frac{Q(t)}{Q(t=0)}=\frac{E L A_{\Delta P_{r e f}=\Delta P}(t)}{E L A_{\Delta P_{r e f}=\Delta P}(t=0)}
$$

where $N L F R$ is the normalized leakage flow rate $(-), Q$ is the leakage flow rate $\left(\mathrm{m}^{3} \mathrm{~s}^{-1}\right)$, $E L A$ is the leakage area of the opening $\left(\mathrm{m}^{2}\right)$, and $t$ is the elapsed time since the beginning of the aerosol injection (s).

\subsection{Normalized sealing rate}

When a leak is being sealed, the temporal derivative of $N L F R$ is a measure of the sealing rate of the crack. Here, we define the normalized sealing rate, NSR, as the temporal derivative of $N L F R$ divided by the approximated ideal aerosol flux to the leak $C Q(t)$ :

$$
\begin{aligned}
N S R & =-\frac{1}{C Q(t)} \frac{d}{d t}\left(\frac{Q(t)}{Q(t=0)}\right) \\
& \approx \frac{\text { Variation of the fraction of the leak sealed per unit time }}{\text { Ideal aerosol flux to the leak }}
\end{aligned}
$$

where NSR is the normalized sealing rate $\left(\mathrm{kg}^{-1}\right), C$ is the aerosol concentration $\left(\mathrm{kg} \mathrm{m}^{-3}\right)$.

\section{Results and discussion}

\subsection{Particle size measurements}

Particle size measurements were performed during three experiments. Figure 4 displays the results of those three experiments on a log-probability scale. On average, the Mass Median Diameter (MMD) was about $4.9 \mu \mathrm{m}$; the mass concentration was about $0.34 \mathrm{~g} \mathrm{~m}^{-}$

3 . The repeatability of the data was very good; therefore, the information collected in these experiments was used in all of the other experiments performed. 


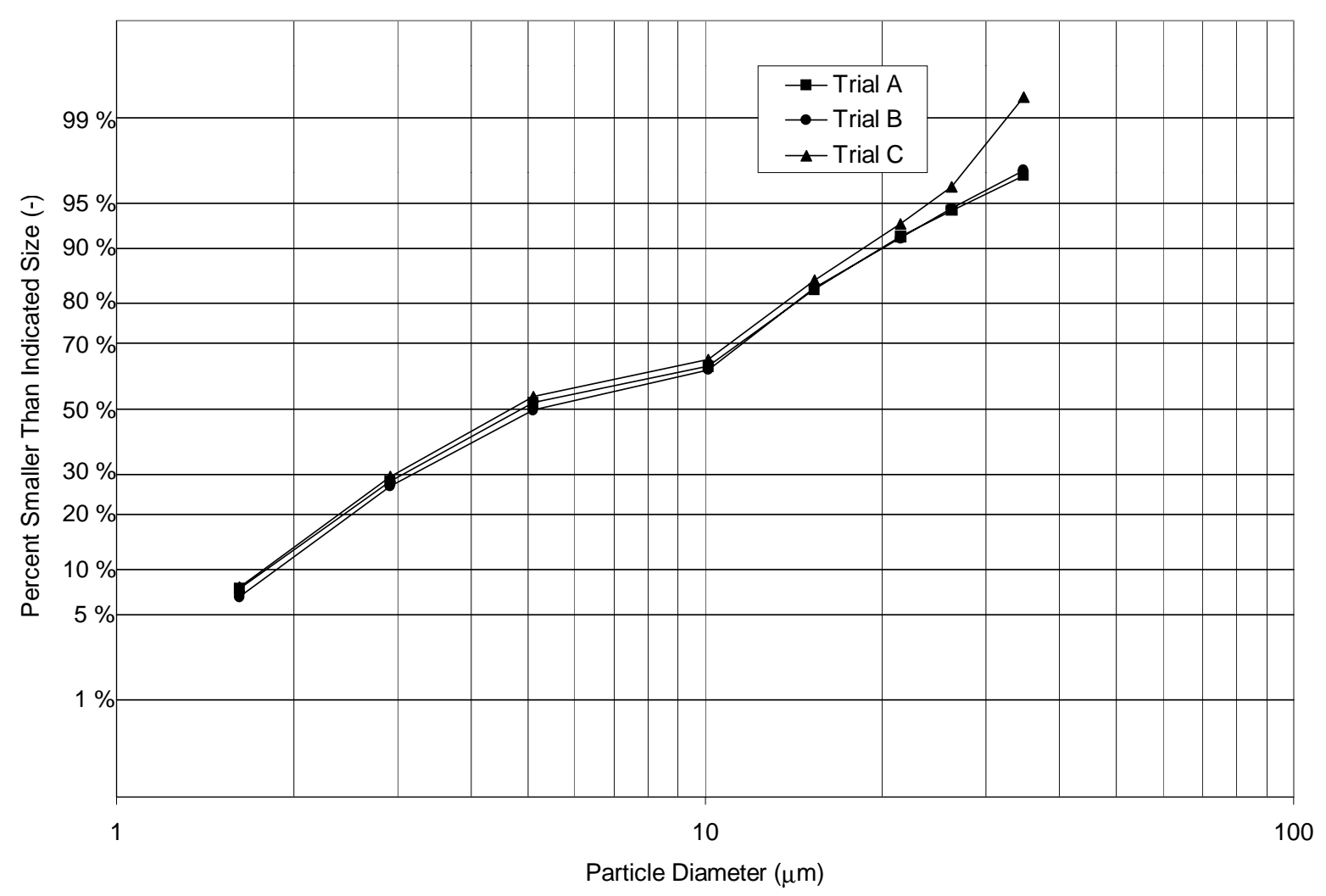

Figure 4. Particle size measurement data displayed on a log-probability scale (mass distribution).

\subsection{Leakage flow time series}

The results of typical experiments are shown in Figure 5. Several important observations are detailed below:

1. Joint-leaks seal considerably faster than slot-leaks do which suggests that the deposition efficiency is lower in the latter;

2. The sealing rate decreases monotonically with time in the joint. However, the sealing rate behavior of the slot seems more complex. For example, in Figure 5, the sealing rate increases during the sealing between 600 and 1200 seconds of elapsed time;

3. The sealing starts as soon as the injection begins;

4. The leakage flow through the slots is reduced by more than $90 \%$ in 20-30 minutes. the same reduction is observed in joints in 15-20 minutes;

5. The repeatability of the sealing process is good.

Note also that the initial leakage flow rate differs between the different types of leaks. This is due to the fact that, although the cross-sectional area of the opening is the same, the joint-leak has more resistance to the flow passage. Therefore, its ELA is smaller and the leakage flow at a given pressure will be smaller than that measured in a slot-leak. 


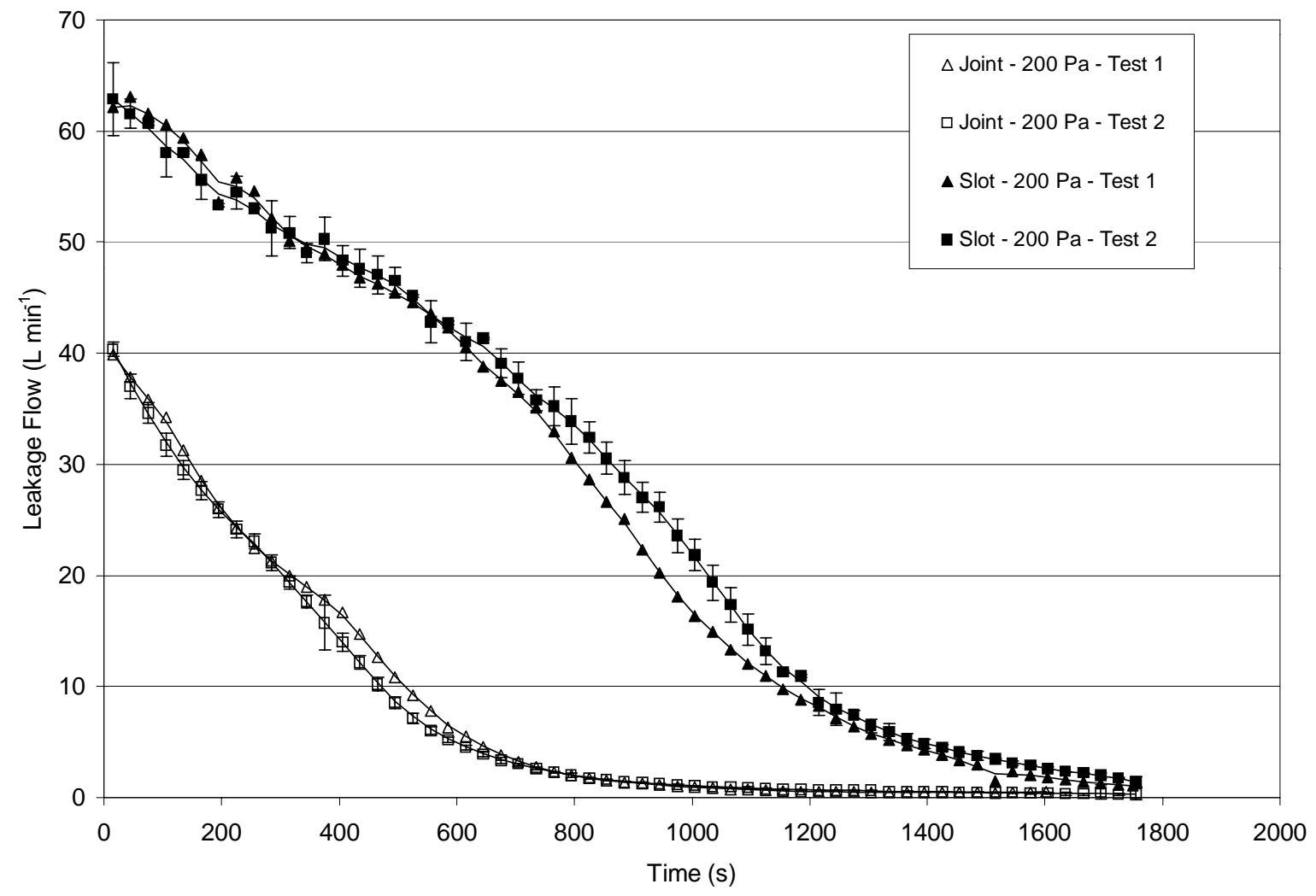

Figure 5. Time-series profile of the plugging of a slot and joint at $200 \mathrm{~Pa}(30$ second averages) for two tests to show repeatability. Error bars are based on the standard deviation of the airflow rate measurement.

\subsection{Deposition patterns}

One interesting aspect of these experiments is the deposition patterns that were found. In the slot-type leaks, the deposition occurred only on the downstream edge because of the main flow (Figure 6. Therefore, although the air velocity in the duct was 10 to 35 times smaller than the velocity through the slot, the main airflow gave significant inertia to the particles.

Davies (1968) has proposed a criterion for determining whether a wind could affect the particle sampling in a tube by comparing the velocity at the stop-distance from the slot to the wind-velocity (here, $U_{o}=0.51 \mathrm{~m} \mathrm{~s}^{-1}$ ). A similar analysis applied to a two-dimensional geometry yields the following criterion:

$$
U_{0}<\frac{1}{5}\left(\frac{Q / H}{\pi \tau}\right)^{0.5},
$$

where $H$ is the slot height (m) and $\tau$ is the particle relaxation time (s). 
Application of this criterion to slot-leaks suggests that only large particles (larger than about $15 \mu \mathrm{m}$ for a $1 \mathrm{~mm}$ leak at $400 \mathrm{~Pa}$ ) are subject to that inertial effect. This result is difficult to reconcile with the size distribution and average deposition efficiencies reported in this paper for this type of leaks. This may be due to the fact that Davies' analysis implicitly assumes Stokesian drag and quasi-stationary motion of the aerosol particles. In our case, the large velocities and large Stokes numbers (based on suction velocity and crack-width) suggest that these assumptions do not hold.

Because the joint-type leaks were made of opaque material, the leaks had to be dismantled to observe early deposition patterns-i.e., the experiment had to be aborted. One experiment performed at $400 \mathrm{~Pa}$ was stopped after about 1 minute of injection. A significant amount of sealant material had deposited on the outer wall of the joint, about 1-2 mm downstream of the leading edge. Similar patterns were found in experiments aborted at more advanced stages. Final deposition patterns consistently showed 6 deposition zones Figure 7):

- Zone 1 starts 1-2 mm from the leading edge. The particles accumulate from the outer wall and bridge the gap. Typically, this deposit represents $80 \%-90 \%$ of the total mass collected in the leak. This is the main cause for the decline of the flow rate;

- Zone 2 is the leading edge where a small amount of particles gathers;

- Zones 3 and 4 consist of a layer of sealant on the outer and inner walls, after the main plug;

- Zone 5 consists of a layer of sealant on the outer wall of the $90^{\circ}$ bend, before the leak exit;

- Zone 6 is located around the inside corner of the upstream leak exit wall.

Zone 1 and 2 could clearly be identified in all experiments. Deposition in zone 1 is due to inertial separation near the entry point where the streamlines converge due to the acceleration of the flow. The deposition in zone 1 being mainly due to impaction, this shows that this phenomenon plays a major role in the sealing of those leaks, as it does in slots. The deposition in zone 2 is believed to occur mainly at the end of the sealing process, as the leak becomes an obstacle to the boundary-layer flow. (This is consistent with the results of one experiment performed with the joint facing backwards: in this case, no deposition occurred in zone 2.) At low pressures, zones 3 and 4 could hardly be seen; however, the surfaces were sticky. The deposition in these zones increased with pressure, as did the deposition in zones 5 and 6.

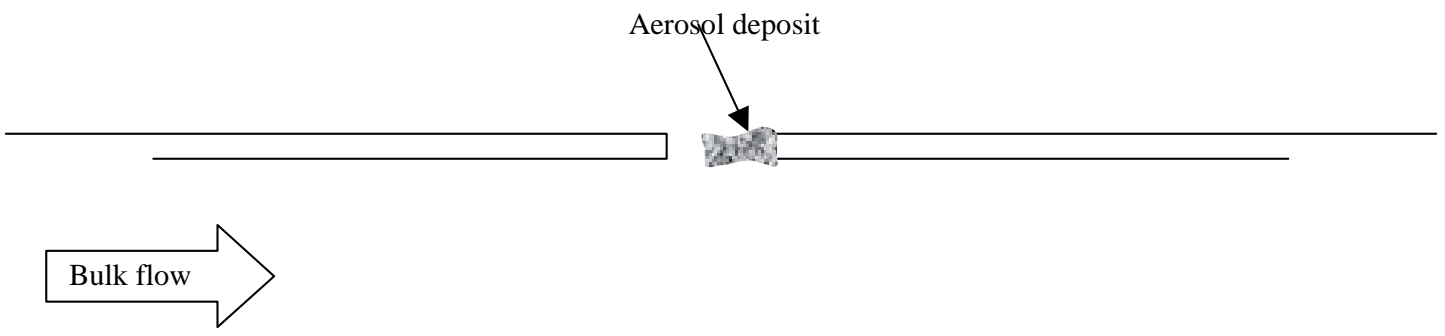

Figure 6. Deposition patterns in slot-type leaks. 


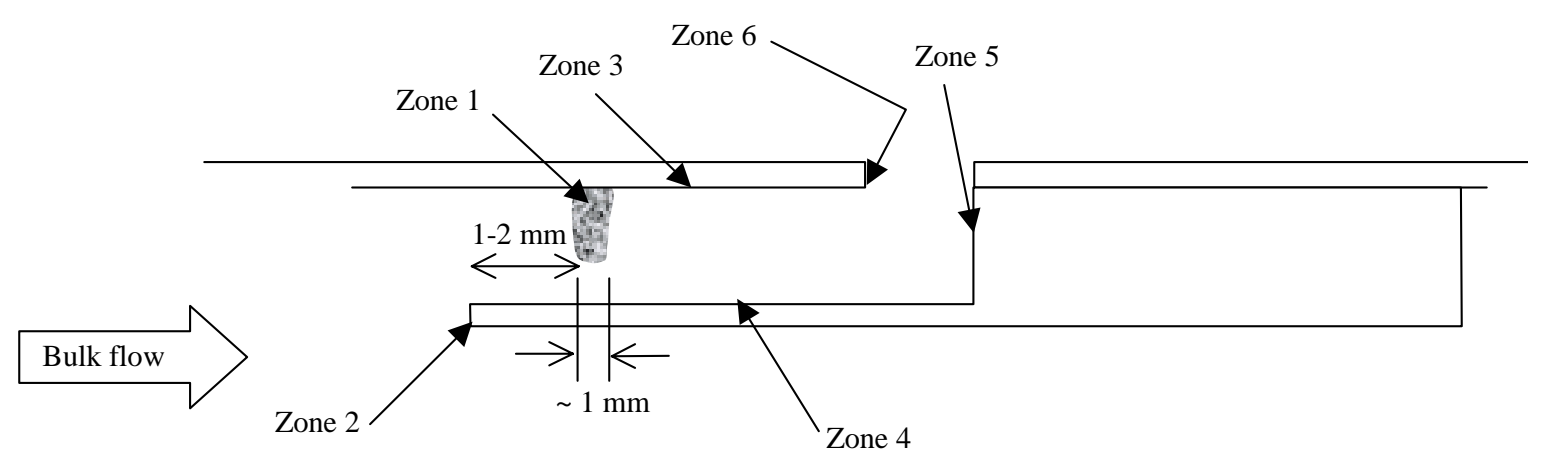

Figure 7. Deposition patterns in joint-type leaks.

\subsection{Average deposition efficiencies}

The average deposition efficiencies are shown in Table 1. Two key conclusions can be drawn:

- the average deposition efficiencies seems to be fairly independent of the pressure; and

- the average deposition efficiency in slot-type leaks is on the order of $25 \%$, whereas it is on the order of $85 \%$ in joint-type leaks. (Note that field leaks probably yield greater deposition efficiencies as the leak walls have irregularities (Carrié and Modera, 1998). Irregularities disturb the flow in the vicinity of the wall and therefore enhance inertial deposition).

The average deposition efficiency in joint-type leaks is surprisingly high. However, remember that those results are biased by the fact that some particles may deposit in the crack although they are not originally in the stream going through the leak. This is likely to happen towards the end of the experiments as the plug acts more or less like an impactor. In fact, the expected Stokes numbers (based on the suction velocity and the initial crack width) are in the range of 1 to 2 for $10 \mu \mathrm{m}$ particles over the range of pressure differentials of interest, i.e., above the value reported by Hinds (1982) for 50\% collection efficiency in a rectangular impactor.

Table 1 and Figure 8 show the aerosol mass (M) that would ideally pass through or deposit in the leaks $\left(\mathrm{M}=\int_{t=0}^{\infty} C(t) Q(t) d t\right)$. It is clear from Figure 8 that the results disagree with Vaughan's model prediction. If they were in agreement with this model, M would be constant for all pressures. In addition, based on the average data at all pressures, the proportionality constants would be about 2 and $0.6 \mathrm{~g} \mathrm{~cm}^{-3}$ for the slot and joint, respectively, i.e., well below the value of $30 \pm 20 \mathrm{~g} \mathrm{~cm}^{-3}$ suggested by Morewitz (1982). This may be due to the fact that Vaughan's model implicitly assume that the aspiration efficiency in the crack is close to unity, which is not the case in our experiments. Another strong assumption of this model that may not hold here is that the collection efficiency depends only on the ratio of the plug to the crack size. 
Table 1. Average deposition efficiencies and ideal aerosol mass entrained into the leaks (M).

\begin{tabular}{|c|c|c|c|c|c|}
\hline Exp. \# & $\begin{array}{c}\text { Type of } \\
\text { Leak }\end{array}$ & $\begin{array}{c}\text { Pressure } \\
\text { Set- } \\
\text { Point } \\
(\mathrm{Pa})\end{array}$ & $\begin{array}{c}\text { Average } \\
\text { Pressure } \\
(\text { Pa) }\end{array}$ & $\begin{array}{c}\text { Average } \\
\text { Deposition } \\
\text { Efficiency (-) (in } \\
\%)\end{array}$ & $\begin{array}{c}\text { Aerosol Mass, M } \\
(\mathrm{mg})\end{array}$ \\
\hline 10 & Joint & 100 & 98 & $75 \%$ & 68 \\
\hline 12 & Joint & 100 & 100 & $84 \%$ & 77 \\
\hline 14 & Joint & 100 & 101 & $83 \%$ & 70 \\
\hline 7 & Joint & 200 & 199 & $80 \%$ & 77 \\
\hline 12 & Joint & 200 & 199 & $96 \%$ & 79 \\
\hline 13 & Joint & 300 & 291 & $85 \%$ & 95 \\
\hline 11 & Joint & 300 & 301 & $94 \%$ & 84 \\
\hline 8 & Joint & 300 & 302 & $81 \%$ & 94 \\
\hline 14 & Joint & 300 & 302 & $96 \%$ & 79 \\
\hline 13 & Joint & 400 & 396 & $91 \%$ & 90 \\
\hline 9 & Joint & 400 & 404 & $88 \%$ & 95 \\
\hline 5 & Slot & 100 & 99 & $24 \%$ & 270 \\
\hline 10 & Slot & 100 & 100 & $26 \%$ & 230 \\
\hline 6 & Slot & 200 & 195 & $24 \%$ & 270 \\
\hline 7 & Slot & 200 & 197 & $28 \%$ & 282 \\
\hline 8 & Slot & 300 & 297 & $25 \%$ & 311 \\
\hline 9 & Slot & 400 & 395 & $30 \%$ & 318 \\
\hline
\end{tabular}




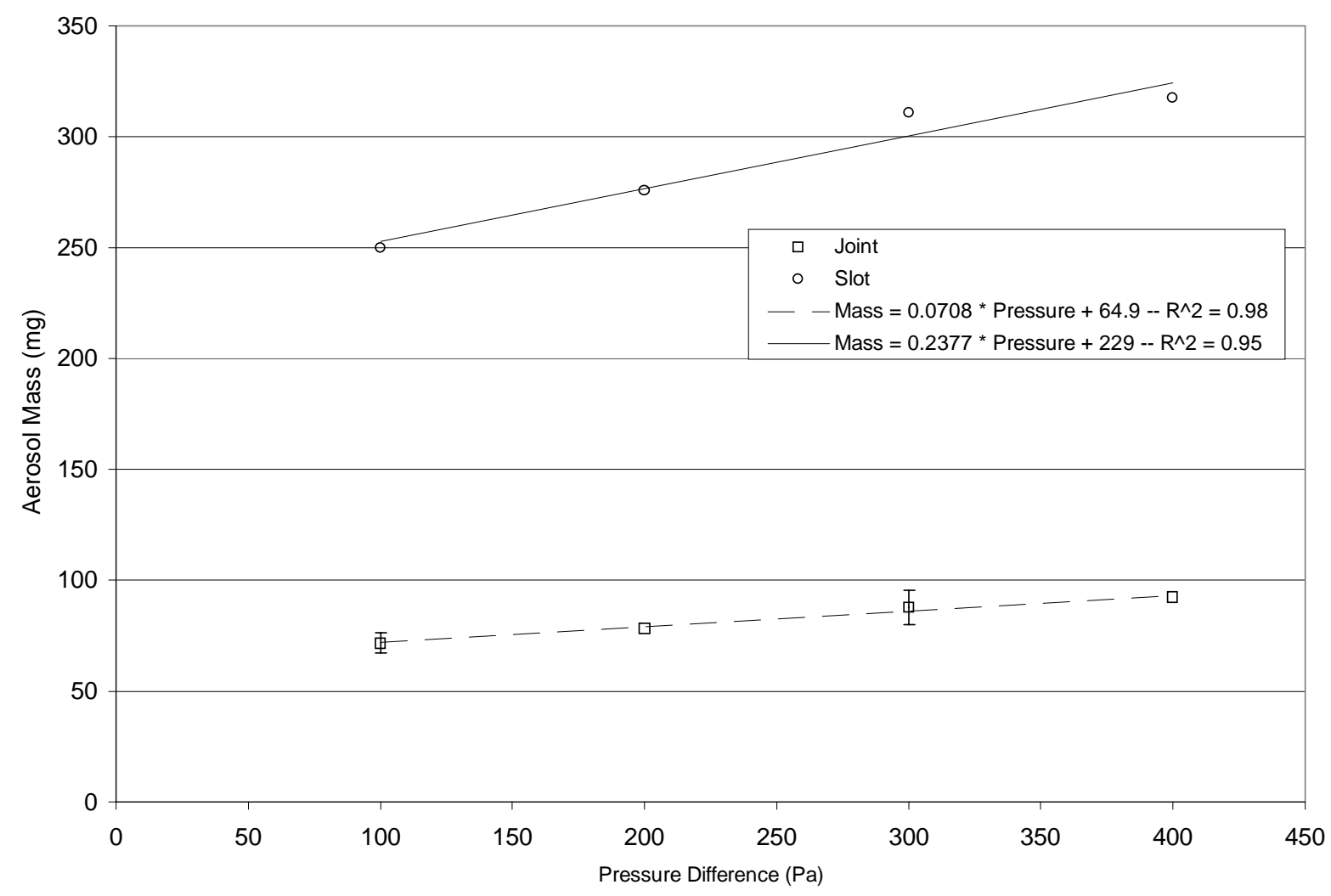

Figure 8. Aerosol mass that would ideally pass through or deposit in the leaks versus pressure difference applied.

\subsection{Normalized sealing rates}

Figure 9 Figure 11 display normalized sealing rates as defined in equation 3. Figure 9 shows that the pressure has little influence on the normalized sealing rates: all the slots seal at approximately the same normalized rate, which is consistent with the deposition efficiency results. Note also that below a normalized leakage flow rate of about 0.2 , the normalized sealing rate seems to decrease a little. One explanation for this effect is that the particles with greater inertia may not be able to curve into the crack because of the smaller radius of curvature of the streamlines. In fact the Stokes numbers (based on the suction velocity and $20 \%$ of the slot-width) lie between 1 and 4 for $5 \mu \mathrm{m}$ particles. Therefore, a significant fraction of the particles originally in the air stream of the leak would be carried away with the main air stream.

For joint leaks, we consistently observed an increase of the sealing rate as the sealing occurred down to a critical leak size located around a normalized leakage flow rate of 0.15 . Below that value, the normalized sealing rate decreases very significantly. This means that the critical leak size corresponds to an effective size of the crack reduced to about $15 \%$ of its initial value. One explanation for this effect is that the path that the 
particles have to follow becomes more tortuous, which may result in some depletion before they reach the plug (see Figure 3).

There is a broad range in the normalized sealing rates for joint-type leaks, especially from normalized leakage flows of 0.3 down to 0.05 (Figure 10,Figure 11). Although the data is noisy due to the fact that normalized sealing rates are based on derivatives, the values found at 100 and $200 \mathrm{~Pa}$ are consistently greater than those found at 300 and $400 \mathrm{~Pa}$. The most likely explanation is that, with the increased complexity of the path through the leak, some deposited particles may not participate as effectively to the sealing at high pressures.

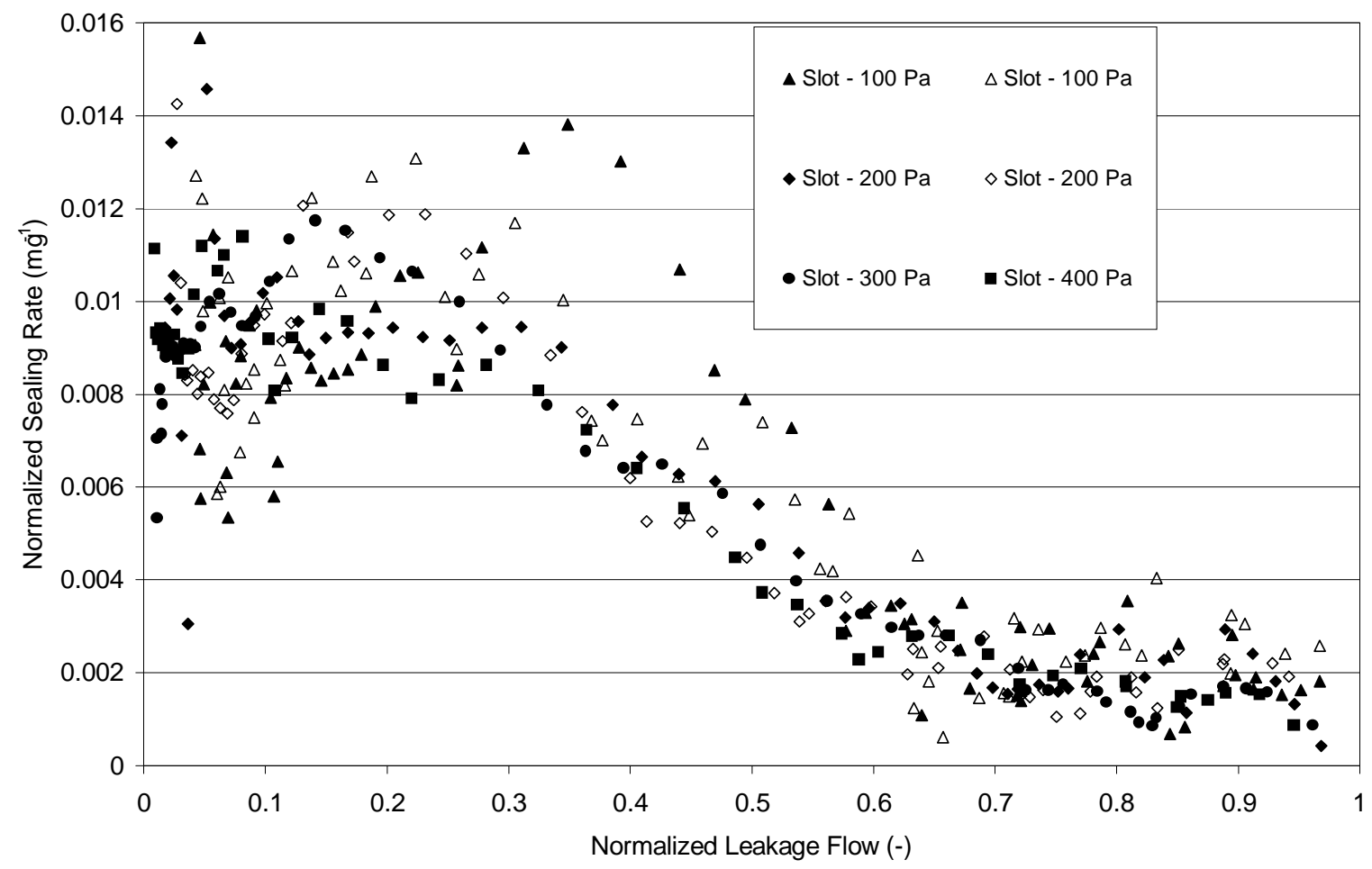

Figure 9. Normalized sealing rates for slot-type leaks. The derivatives were calculated with the smoothed leakage flow data to reduce the noise. Experiments with the same pressure set-point have symbols with the same shape. 




Figure 10. Normalized sealing rates for joint-type leaks (100 and $300 \mathrm{~Pa})$. The derivatives were calculated with the smoothed leakage flow data to reduce the noise. Experiments with the same pressure set-point have symbols with the same shape. 


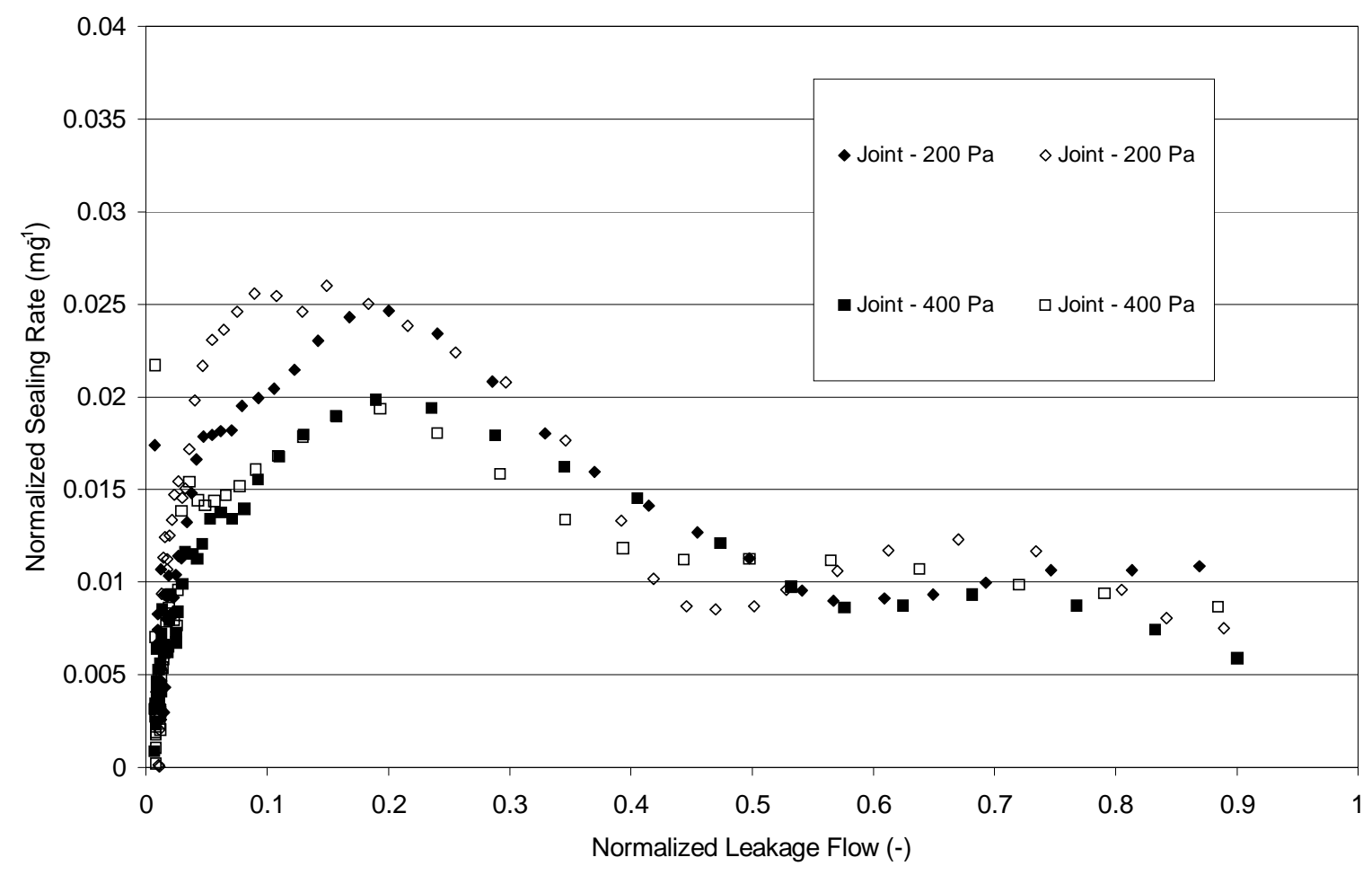

Figure 11. Normalized sealing rates for joint-type leaks (200 and $400 \mathrm{~Pa})$. The derivatives were calculated with the smoothed leakage flow data to reduce the noise. Experiments with the same pressure set-point have symbols with the same shape.

\section{Conclusions}

This study allows us to better understand the sealing process in slot- and joint-type leaks. Three key results are that: a) inertial impaction near the entry point is the major cause of the decline of the leakage flow rate for either types of leaks; b) the pressure variations in the 100-400 $\mathrm{Pa}$ range do not significantly affect the average deposition efficiency; c) the average deposition efficiency of the slot- and joint-type leaks used are in the range of $25 \%$ and $85 \%$, respectively.

Also, there exists a critical joint-leak size below which the normalized sealing rate decreases significantly. Although the critical leak size found in this study was small, further analyses should be performed to see the potential implications for duct-sealing applications.

In addition, the normalized sealing rates obtained suggest that, in the 100-400 Pa range, low pressures would result in a greater sealing effectiveness. This means that the pressure for sealing leaks in a real duct system should be kept low, whereas with the current 
protocol, the pressure keeps increasing as the system is being tightened. The major problem in implementing that technique is that, for a given ELA of a duct system, the bulk airflow rate will also be reduced as we reduce the pressure. This will yield less particle penetration through the ductwork; therefore, it may decrease the overall sealing rate although the NSR might be greater.

There remain unanswered questions regarding the deposition mechanisms in the leaks. The effect of the bulk flow on inertial deposition is difficult to reconcile with a classic analysis of the inertial effect. The possible explanations given in this paper with respect to the normalized sealing rate behavior merit further examination. In addition, the reason why the average deposition efficiency remains nearly unchanged over the 100-400 Pa pressure range remains unclear. These questions are very complex as they are closely linked to the changes in flow dynamics near the entry point as the plug grows. Nevertheless, the experimental and data analysis methods presented here provide an interesting framework for examining the accuracy of predictive models of the sealing effectiveness of low-pressure leaks.

\section{Acknowledgements}

This work was supported by the Assistant Secretary for Energy Efficiency and Renewable Energy, Office of Building Technology and Community Systems, of the US Department of Energy under Contract No. DE-AC03-76SF00098

\section{References}

ASHRAE. 1997. ASHRAE Handbook: Fundamentals, American Society of Heating, Refrigerating, and Air Conditioning Engineers, Inc., Atlanta.

Carrié, F. R. 1994. Obturation de fuites à l'aide d'aérosols: application à la réhabilitation des systèmes de distribution d'air. Thèse de Doctorat: INSA, Lyon, 1994. 155 p.

Carrié, F. R., Andersson, J., and Wouters, P. 1999. Improving Ductwork - A Time For Tighter Air Distribution Systems. Air Infiltration and Ventilation Centre, Coventry, UK.

Carrié, F. R., Bossaer, A., Andersson, J. V., Wouters, P., and Liddament, M. 2000. Duct leakage in European buildings: status and perspectives. Energy and Buildings. 32: 235-243.

Carrié, F. R. and Modera, M. P. 1998. Particle Deposition in a Two-Dimensional Slot from a Transverse Stream. Aerosol Science and Technology. 28: 235-246.

Clement, C. F. 1995. Aerosol penetration through capillaries and leaks: theory. Journal of Aerosol Science. 26: 369-385.

Cummings, J. B., Tooley, J. J., Jr., and Dunsmore, R. 1990. Impacts of Duct Leakage on Infiltration Rates, Space Conditioning Energy Use, and Peak Electrical Demand in Florida Homes, Proceedings of ACEEE Summer Study, Pacific Grove, California, August 1990. American Council for an Energy Efficient Economy, Washington, D.C.

Davies, C. N. 1968. The entry of aerosols into sampling tubes and heads. Journal of Physics. D. Series 2. 1: 921-932.

Fisk, W. J., Delp W. W., Diamond, R. C., Dickerhoff, D. J., Levinson, R., Modera, M. P., Nematollahi, M., and Wang, D. 2000. Duct Systems in Large Commercial Buildings: Physical Characterization, Air Leakage, and Heat Conduction Gains. Energy and Buildings. 32: 109-119.

Hinds, W. C. 1982. Aerosol Technology. Properties, Behavior, and Measurement of Airborne Particles. John Wiley \& Sons. New York, USA. 
Mitchell, J. P., Edwards, R. T., and Ball, M. H. E. 1990. The Penetration of Aerosols Through Fine Capillaries. Int. Journal of Radioactive Materials Transport (RAMTRANS). 2: 101-116.

Mitchell, J. P., Marshall, I. A., Latham, L. J., and Ball, M. H. E. 1992. The Penetration of Aerosols Through Fine Orifices. Int. Journal of Radioactive Materials Transport (RAMTRANS). 3: 5-17.

Modera, M. P. 1993. Characterizing the Performance of Residential Air Distribution Systems, Energy and Buildings. 20(1): 65-75.

Modera, M. P. and Carrié, F. R. 1996. Method and Device for Producing and Delivering an Aerosol for Remote Sealing and Coating, The Regents, University of California. USA, US Patent $N^{\circ}$ 5,522,930. Jun. 4, 1996.

Modera, M. P., Dickerhoff, D. J., Nilssen, O., Duquette, H., and Geyselaers, J. 1996. Residential Field Testing of an Aerosol-Based Technology for Sealing Ductwork. Proceedings of ACEEE Summer Study, Pacific Grove, CA, August 1996.

Morewitz, H. A. 1982. Leakage of Aerosols from Containment Buildings. Health Physics. 42: 195-207.

Morton, D. A. V., and Mitchell, J. P. 1995. Aerosol penetration through capillaries and leaks: experimental studies on the influence of pressure. Journal of Aerosol Science. 26: 353-367.

Novick, V. J. 1994. Plugging Passages with Particles: Refining the Morewitz Criteria. Aerosol Science and Technology. 21: 219-222.

Parker, D., Fairey, P., and Gu, L. 1993. Simulation of the Effects of Duct Leakage and Heat Transfer on Residential Space-Cooling Energy Use, Energy and Buildings. 20(2): 97-114.

Pilat, M., Ensor, D. S., and Bosh, J. C. 1970. Source Test Cascade Impactor, Atmospheric Environment. 4: 671-679.

Sherman, M. H. 1992. A Power-Law Formulation of Laminar Flow in Short Pipes. Journal of Fluids Engineering. 114: 601-605.

Vaughan, E. U. 1978. Simple Model for Plugging of Ducts by Aerosol Deposits. Trans. Am. Nucl. Soc. 28: 507-508.

Williams, M. M. R. 1994. Particle deposition and plugging in tubes and cracks (with special reference to fission product retention). Progress in Nuclear Energy. 28: 1-60. 